\title{
The state of the Irish pharmaceutical industry
}

\author{
"Given the less positive performance of other merchandise sectors, the pharmaceutical sector has now become the \\ dominant exporting sector, accounting for $56 \%$ of Irish merchandise exports in $2011 . "$
}

Keywords: Ireland $₫$ patent cliff $₫$ pharmaceutical industry

The Irish pharmaceutical industry continues to be an international success story and this article outlines the achievements of the industry and discusses the main threats and opportunities for future development. The sector took off in the 1970s following the Industrial Development Authority's adoption of pharmaceuticals as one of its target sectors. This resulted in a series of manufacturing investments, notably by US- and UK-based companies. Currently, Ireland's main strengths in attracting foreign investment in pharmaceuticals include its low rate of corporation tax (12.5\%), its educated labor force, access to the European market, well-developed regulatory capabilities and a supportive industrial development agency.

Since its inception, the pharmaceutical sector in Ireland has experienced strong and nearly continuous employment growth. In 1998, the sector already accounted for approximately 20,000 jobs (pharmaceutical sector is here defined as NACE 21) [101]. Employment continued to grow to approximately 30,000 in 2007. However, numbers fell slightly at the start of the global economic crisis in 2008. Remarkably, employment picked up strongly again, reaching a historic height of 31,000 in 2010, after which numbers again dropped a little in 2011. The growth of employment in the Irish pharmaceutical industry, even at a time when employment in other manufacturing industries started to decline, has significantly increased its relative importance. The share of the pharmaceutical industry in total manufacturing employment has increased from under $6.9 \%$ in 1998 to $14.8 \%$ in 2011 .

The sector's performance in terms of external trade is even more impressive. Exports grew from $€ 24.6$ billion in 2000 to $€ 51.8$ billion in 2011 (pharmaceutical sector is here defined as to include organic chemicals, pharmaceutical preparations and essential oils) [101]. Even during the economic crisis, exports grew continuously. Given the less positive performance of other merchandise sectors, the pharmaceutical sector has now become the dominant exporting sector, accounting for $56 \%$ of Irish merchandise exports in 2011.

The strong export performance is, to an extent, reflected in Ireland's position as a global pharmaceutical exporting nation. UN Comtrade data show that the shares of global pharmaceutical exports recorded for most traditional pharmaceutical exporting countries, such as the UK, Germany and the USA, have all substantially shrunk since the mid1980s. In contrast, Ireland's market share in pharmaceuticals has grown substantially, from $1.9 \%$ in 1985 to $7.8 \%$ in 2005 , after which it fell slightly to $7.2 \%$ in 2010. By 2010 Ireland was the fifth-largest exporter of pharmaceuticals in the world. The recent slight fall in Ireland's share, in spite of the strong export growth figures, is partly explained by the emergence of new pharmaceutical exporting nations, notably China. The Chinese pharmaceutical industry has experienced very strong growth as absolute exports increased more than sixfold between 2000 and 2010.

Aside from these achievements, a number of weaknesses are evident. The Irish pharmaceutical industry remains strongly manufacturing focused. Although many manufacturing subsidiaries have established process $R \& D$ capability, multinational corporations have invested very little in discovery and clinical trials research. Attracting internationally mobile discovery units was not considered a realistic option because, until recently, the relevant science and technology infrastructure was poor by international standards. This has changed profoundly since 2000 , when the Irish Government established a major science and technology funding program in the form of the Science Foundation Ireland.

Another weakness is the fact that Ireland's pharmaceutical industry remains largely

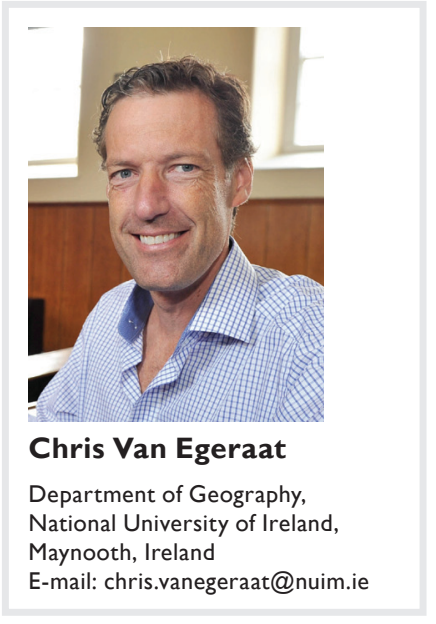

FUTURE
SCIENCE 
dependent on foreign direct investment. In 2003, subsidiaries of foreign companies accounted for 93\% of employment in (manufacturing active) pharmaceutical companies [1]. The Science Foundation Ireland funding has stimulated a growing body of Irish scientists and an increase in indigenous start-up companies. However, the number of start-ups that have brought products to the clinical trial stage is, as yet, relatively small [2].

Notwithstanding these weaknesses, the Irish pharmaceutical industry should be considered a success. However, while the industry's 55\% share of Irish merchandise exports is impressive, it leaves Ireland vulnerable to changes in the external environment. There are two main threats to the further growth and development of the industry: the patent cliff and the incipient offshoring of pharmaceutical activities.

In 2011, the pharmaceutical industry reached the edge of the patent cliff. A large number of major blockbusters are coming off patent in 2011 and 2012. At least six of the top ten global drugs coming off patent are currently produced in Ireland. Global Pharmaceutical Market Review data suggest that prior to patent expiry, these six drugs alone represented global revenues of US $\$ 40$ billion. As soon as these drugs come off patent, their value will be significantly reduced - in some cases literally decimated. Not all the production involved is undertaken in Ireland, but a substantial portion is. The patent cliff will, therefore, have a strong impact on Irish exports.

The precise impact partly depends on several strategic decisions on the side of the originator and generic companies. After expiry, the originator companies may or may not decide to continue production of the drug. They may choose to continue production in Ireland or move offshore. Equally, generic competition may choose to produce the drug in Ireland or, more likely, elsewhere. But whoever ends up producing the drug and wherever it is produced, the value will be significantly reduced - by billions of Euros. As further products come off patent, this issue will continue to haunt Ireland after 2012.

Although the blockbuster drugs coming off patent account for an important share of Irish pharmaceutical exports, they are produced by a relatively small proportion of the pharmaceutical workforce. The direct impact on employment and the future development of the industry will, therefore, be relatively limited. Indeed, it may be the incipient outsourcing and offshoring activities by pharmaceutical companies that pose the greater threat.

In the context of reduced rates of revenue growth and increasing costs, an increasing number of companies have begun to outsource noncore activities. Some companies have started to outsource the early stages of the active ingredient synthesis cycle. Moving back into the synthesis chain, the regulatory requirements tend to be lower and, as a result, skill requirements and the level of regulation diminish. Partly due to Ireland's rapidly rising wage levels of the Celtic Tiger era, very few processes are outsourced to companies in Ireland. Over the last decade, the pharmaceutical companies have increasingly used low-cost suppliers in India and China, mainly for lower value-added supplies. Most pharmaceutical companies remain reluctant to offshore/outsource the later-stage synthesis to companies in India and China, doubting whether these countries have the requisite technical knowledge and can meet the standards required to supply the highly regulated markets. This perception is changing, however, and pharmaceutical companies have even begun to contemplate setting up their own active ingredient plants in China and India [1].

\section{"At least six of the top ten global drugs coming off patent are currently produced in \\ Ireland ... The patent cliff will therefore have a strong impact on Irish exports."}

In the face of a reduction in the number of blockbusters coming out of the development pipelines and increased competition from other countries as locations for pharmaceutical production, subsidiaries in Ireland have identified opportunities to reposition themselves in the global production networks of their parent companies. Most subsidiaries are developing into strategic launch plants and flexible multiproduct plants, capable of producing the high value-added stages of the chemical synthesis chain as well as the smaller volume, high-value, niche products. Building a core capability in these more regulated and skill-intensive activities is one opportunity to cement the chemical pharmaceutical industry in Ireland.

Additional opportunities lie in the area of process $R \& D$. Driven by a search for greater efficiencies in the process $R \& D$ development chain, pharmaceutical companies are increasingly co-locating process $\mathrm{R} \& \mathrm{D}$ functions 
with their main overseas manufacturing operations [3]. Apart from providing new jobs, the establishment of such activities will lead to significant skill upgrading. A survey of Irish pharmaceutical companies has shown that between 2001 and 2006 the number of staff involved in process $\mathrm{R} \& \mathrm{D}$ almost doubled, from 408 to 800 . A total of $30 \%$ of the employees involved hold a $\mathrm{PhD}$ degree [4].

\section{"Probably the greatest hope for the development of the pharmaceutical industry lies in biopharmaceuticals."}

Probably the greatest hope for the development of the pharmaceutical industry lies in biopharmaceuticals. Since 2000, Ireland has been emerging as an increasingly important location for biopharmaceutical fermentation plants. Ireland now has over ten large-scale biopharmaceutical facilities. During the last year alone six blue-chip companies invested in biopharmaceutical facilities, announcing over 850 jobs. The rise of biotechnology, besides providing additional jobs, has the potential to change Ireland's relative role in global manufacturing networks. Compared with chemical pharmaceuticals, biopharmaceutical production requires even more highly skilled staff and a greater process R\&D effort. In most cases, the Irish facility is one of only one or two facilities outside a company's home country, making it a strategic facility supplying global markets from the beginning.

\section{References}

1 Van Egeraat C, Barry F. The pharmaceutical industry over the boom period and beyond. Irish Geogr. 42(1), 23-44 (2009).

2 Curran D, Van Egeraat C, O'Gorman C. New Entrants and Inherited Competence: the Evolution of the Irish Biotech Sector. National

In conclusion, the Irish pharmaceutical industry is in a healthy state. The patent cliff will mainly affect exports and will have a more limited effect on employment. The threat of offshoring of chemical synthesis activities will at least be partially offset by new investments in biopharmaceuticals. The main challenges for the medium term will be to diversify from manufacturing-oriented activities to higher value-added $R \& D$ functions and a greater involvement of indigenous actors and resources. The presence of a manufacturing-oriented cluster is only of limited benefit in this regard. Discovery functions require different skill sets that are, as yet, in short supply in Ireland [1]. Diversification into discovery will basically require the development of a separate research-based cluster. The recent Science Foundation Ireland funding is unlikely to attract the large-scale discovery units of the global drug companies, not even in the medium term. The more realistic route will involve the slower process of developing an indigenous capacity, in the form of university spin-outs and private sector spin-offs.

\section{Financial \& competing interests disclosure}

The author has no relevant affiliations or financial involvement with any organization or entity with a financial interest in or financial conflict with the subject matter or materials discussed in the manuscript. This includes employment, consultancies, honoraria, stock ownership or options, expert testimony, grants or patents received or pending, or royalties.

No writing assistance was utilized in the production of this manuscript.

Institute for Regional and Spatial Analysis, Maynooth, Ireland (2011).

3

Van Egeraat C, Breathnacht P. The drivers of transnational subsidiary evolution: the upgrading of process $R \& D$ in the Irish pharmaceutical industry. Regional Studies 46(5), 290-315 (2012).
4 Van Egeraat C. The scale and scope of process $\mathrm{R} \& \mathrm{D}$ in the Irish pharmaceutical industry. Irish Geogr. 43(1), 35-58 (2010).

Website

101 Central Statistics Office. www.cso.ie 